\title{
Innovation and Corporate Conservatism*
}

\author{
Mariagiovanna Baccara ${ }^{\dagger}$ and Ronny Razin ${ }^{\ddagger}$
}

First version: 2005, This version: April 2009

\begin{abstract}
In this paper, we study the incentives of firms to promote innovation. We analyze a situation in which an employee in a firm is inspired with an idea for a new product. In a framework in which intellectual property rights on ideas are imperfect, we analyze the employee's decision of whether to disclose the idea within the firm, to stay silent and maintain the stausquo, or to form a spin-out firm. Next, we look at the owners of the original firm and analyze their incentives to promote creativity among employees. We show that firms may have incentives to discourage both internal disclosure (fearing the reshuffling of rents within the firm caused by an intra-firm renegotiation) and spinout formation (fearing the increase in market competition that a new firm generates). However, we show that innovation bonuses, when possible, mitigate these problems and guarantee that innovation always takes place. Finally, we analyze how the governance structure affects the firm's incentives to promote innovation.
\end{abstract}

\section{Introduction}

The management of innovation represents an increasingly central problem for firms' survival and growth. Imperfect intellectual property rights' enforcement, the risk of information

\footnotetext{
*This paper was previously circulated under the title "Curb Your Innovation: Corporate Conservatism in the Presence of Imperfect Intellectual Property Rights." We thank Jim Anton, Heski Bar-Isaac, Patrick Bolton, Adam Brandenburger, Scott Hemphill, Tracy Lewis, Steve Klepper, Fausto Panunzi, James Rauch, Klaus Schmidt, Jan Zabojnik and the participants of presentations at SED, NYU IO day, University of Bologna, NYU, CRES Conference at Washington University, AAE World Meetings, the Business Law and Innovation Conference at Columbia Universityand the SCIP Financial Law and Innovation Conference at USC. We aknowledge NSF for partially funding this project with grant \#0317634.

${ }^{\dagger}$ Department of Economics, Stern School of Business, 44 West Fourth Street, Room 772, New York, NY 10012. Email: mbaccara@stern.nyu.edu

${ }^{\ddagger}$ Department of Economics, London School of Economics, Houghton Street, London WC2A 2AE, United Kingdom. Email: r.razin@lse.ac.uk.
} 
leakage and the non-contractability of certain aspects of innovation, together, imply that neither firms nor individual innovators can fully appropriate the rents generated by new ideas. Indeed, the division of the rents generated by innovation is often determined by expost renegotiations. ${ }^{1}$ In these renegotiations, the public nature of innovative idea affects the bargaining position of all parties involved. In turn, the anticipation of this renegotiation affects the employees' innovative behavior and the ex-ante efficiency of firms' policies regarding the management of innovation. ${ }^{2}$

Indeed, firms differ substantially in the ways they approach and foster innovation. For example, much has been written about the corporate culture of the Silicon Valley firms, and how their views contrast with the traditional structure of high-tech firms. ${ }^{3}$ While some firms actively promote employees' creativity through intra-firm policies (e.g., encouraging cross-department communication, creating independent units within the organization, etc.) and monetary incentives (e.g., setting MBOs, innovation bonuses, etc.), others are more cautious and often tend to suppress innovative behavior. ${ }^{4}$

The traditional approach to managing innovation has focused on how a firm can encourage innovation from within. ${ }^{5}$ However, a more recent critical approach highlights the risks associated with innovation, such as spin-out formation and the disruption of established and successful production processes. ${ }^{6}$ Thus, the management of innovation involves a complicated balancing act of harvesting innovation while containing it within. To complicate matters, innovation often requires bringing new players into the firm (innovators,

\footnotetext{
${ }^{1}$ Indeed, for some work that specifically addresses ex-post intra-firm bargaining, see Stole and Zwiebel (1994) and Wolinski (2000).

${ }^{2}$ For example, see Anton and Yao (1995) for a model in which inefficient spin-out formation occurs.

${ }^{3}$ E.g., see Saxenian (1996) and references therewith.

${ }^{4}$ One interesting example is the corporate culture at RCA, led by David Sarnoff, in the 1920s and 1930s. As the leading company in the race to produce the first television, the corporation was one of the first to formulate a coherent innovation mangement strategy to protect its position as a monopolist in the radio market and the future television market: as a result, RCA was able to keep its position as a monopolist in both markets for many years, delaying the progress of further innovation such as the FM radio, and the introduction of commercial television. RCA's main strategy relied on high salaries for its engineers, on the one hand, and on a strict internal policy about how innovation was remunerated, on the other. Indeed, the company had a strict policy, dictating that the employee who invented a patentable product had to sign over his rights for the invention in return for one dollar. In particular, Schwartz (2002) chronicles the story of an RCA engineer who, in spite of this policy, pasted all his one-dollar checks on the wall of his office - until the accounting department, upset with the unresolved book balance, steamed them off and forced him to cash them.

${ }^{5}$ For example, "Total Quality Management" is a management approach by which both management and employees become involved in the continuous improvement of the production methods.

${ }^{6}$ See Anton and Yao (1995) and Christiansen (1997), respectively.
} 
venture capitalists or new management). This implies a potential tension between old and new players over the firm's rents as its power structure changes. One manifestation of such changes is the "founders' syndrome" in which the firm's original founders find themselves marginalized as the firm takes new paths. ${ }^{7}$

In this paper, we analyze firms' innovation-management strategies in anticipation of the effects of innovation described above. In particular, our model focuses on a firm producing an original patented product whose production requires one employee, with an outside option normalized to zero. There are three periods, $t=0,1,2$. In period $t=0$, the firm formulates its innovation-management strategy by offering the employee a contract. In period $t=1$, the employee has the possibility (taking advantage of the knowledge acquired in the firm) of discovering innovative ideas. We model this possibility by assuming that the employee decides whether to exert a costly effort in order to discover an idea for a new product.

If the employee discovers a new idea at $t=1$, there are several actions he might take at $t=2$. First, the employee can leave the firm and form a spin-out, without disclosing the idea internally. Second, the employee has the option to keep his idea to himself without implementing it, maintaining his current contract and position in the firm.

Finally, the innovator can disclose his idea within the firm. We assume that whenever ideas are disclosed, the information leaks to all parties involved in their approval and development. ${ }^{8}$ If an idea is disclosed internally, this opens up the possibility for the employee and for the other players who learn the information to renegotiate their contracts within the firm. The outcome of this renegotiation is modeled by a multi-agent Nash bargaining game and depends on the bargaining power of the players involved and on their outside options, in case of a renegotiation breakdown. In particular, the innovator's outside options include the possibility of staying employed under the initial contract and of leaving the firm and forming a spin-out. In the latter case, since information leakage occurred upon internal disclosure, the original firm could compete, to some extent, with the spin-out on the new product market. Thus, the renegotiation outcome crucially depends on the intellectual property rights (IPR henceforth) legislation and its enforcement: If the employee has the legal tools to protect himself against the risk of information leakage, his outside option in the renegotiation is relatively high. On the other hand, if the firm has IPR over

\footnotetext{
${ }^{7}$ See McNamara (1999).

${ }^{8}$ This implies that it is not possible to introduce an idea and convince others about its potential without revealing important aspects of it.
} 
its employees' innovation, the outside option of the innovator is relatively low.

We analyze the effect of the contract at $t=0$ on the decisions of the employee in the subsequent stages. A contract takes the form $\left(v, v_{I D}\right)$, where $v$ is the payment to the employee in the status quo, and $v_{I D}$ is the payment promised to the employee if he discloses a new idea within the firm.

By choosing the initial contract, the firm affects the employee's incentives in two fundamental ways: First, by setting $v$ above the expected rents from both a spin-out and an internal disclosure, the firm can discourage the innovator from being innovative. Second, the firm can manipulate the innovator's outside option in the renegotiation. Indeed, if the firm sets $v_{I D}$ high enough (in particular, higher than the innovator's payoff in a spin-out after the information has been leaked within the firm), the innovator's threat of forming a spin-out upon negotiation breakdown loses credibility, and the firm effectively succeeds in protecting its bargaining position at a relatively low price.

Initially, in Section 3, we analyze the optimal contract problem in the case in which internal disclosures are hard to verify in court. This implies that the payments specified in the contract cannot be conditional on an internal disclosure-that is, $v=v_{I D}$. The optimal contract in this case depends on the employee's bargaining position. If it is strong, the firm's main concern is the potential threat of an internal disclosure. In particular, an employee with a strong bargaining position will be able to appropriate a large part of the innovation rents at the expense of the original firm's owners ( "reshuffling effect"). On the other hand, when the employee's bargaining position is relatively weak, he is more inclined to leave the firm and form a spin-out. The main problem that the firm faces in this case is its own inability to commit not to expropriate the employee's invention if he were to disclose his idea internally ( inner hold-up").

Our results show that sometimes the firm's optimal policy involves discouraging innovation by setting a high status quo compensation, $v$, for the employee. In the former case (Proposition 1), this strategy aims to avoid internal disclosure and the reshuffling of rents in the firm caused by an intra-firm renegotiation. In the latter case (Proposition 2), this strategy aims to prevent the formation of spin-outs. The firm's decision depends on the cost of discouraging the employee from being innovative, and the harm that innovation causes to the firm. The incentives to discourage innovation are higher when the firm's bargaining position vis-a-vis the employee is weaker and when spin-outs cause high losses to the original firm.

While, in many cases, internal disclosure is hard to verify, there are examples of firms 
that have successfully implemented bonus schemes aimed to encourage innovation. ${ }^{9}$ The ability of these firms to sustain such remuneration policies could be due to strong reputational concerns that allow them to commit to a payment to be paid upon an employee's disclosure of a new idea.

To analyze the effects of the introduction of innovation bonuses, in Section 4, we consider the case in which internal disclosure is verifiable $\left(v \neq v_{I D}\right)$. In Proposition 3 , we show that innovation bonuses are a contractual tool powerful enough to always promote innovation within the firm and implement the bargaining efficient outcome in equilibrium. The intuition for this result is the following. First, an innovation bonus $v_{I D}$ allows the firm to prevent undesirable outcomes using a contractual tool that does not necessarily imply stifling innovation, as in the $v=v_{I D}$ case; second, recall that the firm is able to manipulate the employees' outside options in an intra-firm renegotiation by setting $v_{I D}$ at a level high enough to make the threat of a spin-out non-credible. Thus, the firm can always prevent both an undesirable intra-firm renegotiation (reshuffling effect) and the inner hold-up problem, while promoting internal disclosure at the same time, by setting the innovation bonus $v_{I D}$ equal to the innovator's profit in a spin-out, and the status quo payment at $v=0$.

The results discussed above depend on the fact that the firm has the ability to manipulate the innovator's outside option in the bargaining. This suggests that the employee has a strategic interest in committing to leave the firm upon a renegotiation breakdown. Indeed, by being the first player aware of the idea initially, the innovator is a natural first mover. Thus, he might be able to take measures to commit to such a threat before disclosing his idea to anyone within the firm. In Section 5.2, we examine the robustness of the prediction of Proposition 3 to this possibility. Proposition 4 shows that, even if the employee can commit to his outside option, the firm always encourages innovation and internal disclosure always occurs in equilibrium.

However, in Proposition 4, we show that the innovator's commitment ability enables the innovator to appropriate more rents from his idea at the expense of the firm's profits. In particular, if the innovator's bargaining position in the renegotiation is strong, the firm now has to pay the innovator his full bargaining payoff. In turn, this suggests that the firm may have an incentive to introduce a policy to shut down ex-ante any intra-firm contract renegotiation, using only innovation bonuses to promote internal disclosure. In Proposition 5 , we show that, by committing to a no-renegotiation policy, the firm can restore the profits

\footnotetext{
${ }^{9}$ Examples are innovation bonuses paid by many Japanese companies, as well as reward schemes connected to an internal database for collecting and processing new product ideas (see Herstatt and al. (2006)).
} 
that it was able to appropriate in the absence of innovator's commitment ability (i.e., the firm's profits in Proposition 3). ${ }^{10}$

Finally, while in the previous results both the original firm and the spin-out are assumed to be one decision-maker, in Section 5.2, we explore the interplay between our results and the governance structures of the original firm and the spin-out. In particular, since an intrafirm renegotiation reshuffles the rent division within the firm and possibly brings about new players needed to develop the idea, the introduction of innovation affects different ownership structures in different ways. In Proposition 6, we show that the owners of firms with a small number of shareholders tend to be affected more by the reshuffling effect and thus tend to discourage innovation more than firms with a large ownership. In Proposition 7 , we show that spin-outs are less likely to occur the higher is the number of new players required to develop the idea in the spin-out. This is because if many new players are needed, the appropriation rate of the innovator in the spin-out is low, and discouraging innovation (which requires paying only the innovation's payoff in the spin-out) is cheaper to achieve.

The rest of the paper is organized as follows. After a literature review, we introduce the model in Section 2. In Section 3, we study the case in which an internal disclosure is non-verifable by a court, and, in Section 4, we turn to the case of verifiable internal disclosure. Section 5 includes two extensions of our model: the case in which the innovator is able to commit to an outside option, and the link between the corporate governance of the firm and incentives to promote innovation. In Section 6, we conclude.

\section{$1.1 \quad$ Literature Review}

Anton and Yao (1994), Baccara and Razin (2007), d'Aspremont, Bhattacharya and GerardVaret (2000) and Bhattacharya and Guriev (2004) analyze innovators' informational concerns. The patterns of incremental research and worker mobility have been analyzed in works by Scotchmer (1991 and 2005), Anton and Yao (1995), Klepper (2001), Franco and Filson (2002) and Lewis and Yao (2003). Among these, the most relevant reference for our approach is Anton and Yao (1995), which focuses on an innovator's decision regarding whether to leave the firm and form a spin-out. Anton and Yao's paper shares our emphasis on information leakage, and as in our paper, the risk of information leakage modifies the innovator's incentives to reveal his idea within the firm and may result in inefficient spin-

\footnotetext{
${ }^{10}$ Note that this is consistent with RCA's one-dollar policy described in Footnote 3 above.
} 
outs. Moving one step further in this direction, we highlight how this problem affects the incentives to curtail innovation within the firm, as well as the link between these incentives, the legal environment and the governance structure.

Several aspects of spin-out formation, which are different from the focus of this paper, have been analyzed by Pakes and Nitzan (1983), Hellman and Perotti (2005), Hellmann (2005) and Franco and Mitchell (2005) and Rauch and Watson (2004). Pakes and Nitzan (1983) analyze the optimal contract problem for personnel that may leave the firm to form spin-out enterprises. Hellman and Perotti (2005) model the difference between intrafirm innovation and innovation through spin-out as a difference in the level of protection of intellectual property rights. Hellmann (2005) provides a model that describes how alternative corporate policies can affect the rate at which new ideas are generated. Finally, Franco and Mitchell (2005) and Rauch and Watson (2005) study the impact of the legal environment (and, more precisely, the presence of non-compete covenants) and the workers' financial constraints on the rate of entrepreneurship in the economy. ${ }^{11}$

Finally, our analysis formalizes the notion that large established firms are often stagnant and prone to dissolution by small innovative spin-outs. Explanations for this puzzle are often based on unawareness or bounded rationality of established firms when making decisions regarding new technologies. In particular, Christensen (1997) suggests that established firms tend to focus too much attention on their current customer base, not realizing that existing customers are not necessarily the best predictors of tomorrow's market trends.

\section{The Model}

Assume that there is a firm producing a patented product and that production requires labor as input. Let us assume for simplicity that in order to produce, the firm needs to hire exactly one employee. Potential employees have a reservation value of zero.

There are three periods, $t=0,1,2$. In period $t=0$, the firm selects a contract to offer to the employee. At $t=1$, while working for the firm, the employee decides whether to

\footnotetext{
${ }^{11}$ Note that this paper shares with Rauch and Watson (2005) an interest in the factors that may lower the entry rate of spin out in the economy. However, our analysis and focus differ from theirs since, while we assume throughout that the employee is financially constrained at $t=0$, we study the problem of an innovative employee facing contract renegotiation in the presence of information leakage. Instead, they focus on an employee who, after given access to a client, faces a contract renegotiation with the possibility of continuing to serve the client by himself, within the limits set by a non-convenant agreement.
} 
exert a costly and unobservable effort to discover an innovative idea for a product. Let the cost of effort be $c>0$. For the sake of simplicity, we assume that if the employee decides to exert the effort, he discovers a new idea with probability one. ${ }^{12}$ If he discovers a new idea the period before, at $t=2$, the innovator must decide whether to disclose his idea within the firm (and possibly renegotiate his contract), to leave the firm to form a rival spin-out firm (without disclosing his idea internally first), or to keep his idea to himself and remain in the firm under his original contract. We describe the game in detail below.

\subsection{Market Structure Assumptions}

The market can accommodate two firms, the incumbent firm $(F)$ and a potential entrant $(S)$, and two products, the original product $(O)$ and the new one $(N)$. The profits for firm $j \in\{F, S\}$, are given by $\pi_{j}(\rho)$ where $\rho \in\{(O, \emptyset),(N, \emptyset),(O, N),(N, N)\}$ represents one of the following market configurations: $(O, \emptyset)$ is a market in which there is only the incumbent producing the old product; $(N, \emptyset)$ is a market in which there is only the incumbent producing both the old and the new products; $(O, N)$ is a market in which the incumbent produces the old product and the entrant produces the new product; and $(N, N)$ is a market in which both the incumbent and the entrant may produce the new product. Some degree of substitutability between the old and the new products implies $\pi_{F}(N, \emptyset) \geq \pi_{F}(O, N)+\pi_{S}(O, N)$. Moreover, there is rent loss due to competition in the new-product market-i.e., $\pi_{F}(N, \emptyset) \geq \pi_{F}(N, N)+\pi_{S}(N, N)$. Finally, we have $\pi_{F}(N, \emptyset) \geq \pi_{F}(O, \emptyset), \pi_{F}(O, N) \leq \pi_{F}(N, N)$ and $\pi_{S}(O, N) \geq \pi_{S}(N, N)$.

This framework allows to capture different IPR regimes, and innovation types. For example, if the innovative employee can acquire full IPR on his idea before disclosing it within the firm, the incumbent is not able to profit from it even if he is in the position of producing it. In this case, we have $\pi_{F}(O, N)=\pi_{F}(N, N) \leq \pi_{F}(O, \emptyset)$ and $\pi_{S}(O, N)=$ $\pi_{S}(N, N)>0$; if the incumbent has full IPR on all new ideas developed by his employees, then $\pi_{F}(O, N)=\pi_{F}(N, N)>\pi_{F}(O, \emptyset)$ and $\pi_{S}(O, N)=\pi_{S}(N, N)=0$. Moreover, if the new product is an innovation that puts the old product out of the market, then $\pi_{F}(O, N)=$ 0 ; if the new product does not compete with the old one, then $\pi_{F}(O, \emptyset)=\pi_{F}(O, N)$, and so on.

Note that bargaining efficiency requires the incumbent to implement the new product in-house and to realize the surplus of $\pi_{F}(N, \emptyset)$.

\footnotetext{
${ }^{12}$ In Section 6, we discuss the implications of modifying this assumption.
} 


\subsection{The Incumbent's Problem}

At $t=0$, the incumbent offers the employee a contract. The contract takes the form $\left(v, v_{I D}\right)$, where $v$ is the payment to the employee in the status quo, and $v_{I D}$ is the payment if the employee discloses a new idea within the firm. ${ }^{13}$

We impose the following restrictions on the feasible contracts: (i) The employee is financially constrained-i.e., $v, v_{I D} \geq 0$; (ii) In the analysis in Section 3, the disclosure of a new idea within a firm is non-verifiable by a court, implying $v=v_{I D}$ (in Section 4 , we relax this assumption).

\subsection{The Employee's Problem}

At $t=1$, the employee decides whether to invest $c$ to discover a new idea. If he does, he has three choices at $t=2$ :

1. The employee remains silent and gets $v$, while the firm receives $\pi_{F}(O, \emptyset)-v$.

2. The employee discloses the idea within the firm. The ensuing renegotiation of his contract (see below) will determine the rent division between the incumbent and employee.

3. The employee leaves the firm without disclosing his idea, forms a spin-out, and appropriates $\pi_{S}(O, N)$, while the incumbent gets $\pi_{F}(O, N) \cdot{ }^{14}$

If the employee doesn't invest $c$, the game ends after $t=1$, and payoffs are $v$ for the innovator and $\pi_{F}(O, \emptyset)-v$ for the incumbent. We assume that the cost of effort $c$, while strictly positive, is very low. In particular, we assume $c<\min \left\{\pi_{F}(N, \emptyset)-\pi_{F}(O, \emptyset), \pi_{S}(O, N)-\right.$ $\left.\pi_{S}(N, N)\right\}$.

\subsection{Renegotiation upon Internal Disclosure}

If the employee decides to exert the effort to be innovative and discloses the idea within the firm he is working for, a renegotiation of his contract will ensue. We address two aspects

\footnotetext{
${ }^{13}$ It is immediate to see that, if the firm can impose a penalty on the employee for leaving the firm, it will always set this penalty as high as possible. Therefore, for simplicity, we set the maximal penalty to be zero.

${ }^{14}$ Note that in this setting we do not allow the employee to join a different established firm, where he would face another negotiation with the risk of idea expropriation. This possibility, of endogenously unfolding negotiations with information leakage, is analyzed in a full-blown bargaining protocol in Baccara and Razin (2007).
} 
of the renegotiation that takes place between the inspired employee and the firm. The first aspect is that of information leakage: Since intra-firm bargaining requires a discussion about a new idea, we assume that all the parties involved in the bargaining learn the content of the idea. ${ }^{15}$ The second issue is that of outside options: If the intra-firm bargaining breaks down, the firm's and the innovator's outside options are not independent of each other. In particular, upon bargaining breakdown, the innovative employee can still decide whether to leave the firm and form a spin-out (which would yield a payoff of $\pi_{S}(N, N)$ for the employee and $\pi_{F}(N, N)$ for the firm), or to stay in the firm under the original contract (which would yield a payoff of $v_{I D}$ for the employee and $\pi_{F}(N, \emptyset)-v_{I D}$ for the firm). In our analysis, we assume that, if the bargaining breaks down, the employee will choose to maximize his outside option. This amounts to requiring that the employee cannot commit to a course of action upon renegotiation breakdown prior to disclosing the idea. Thus, he will leave the firm if and only if $\pi_{S}(N, N) \geq v_{I D} \cdot{ }^{16}$ The outside option payoffs of the incumbent and the employee implied by the (optimal) choice of the employee are, respectively,

$$
\begin{array}{ll}
\left(\pi_{F}(N, N), \pi_{S}(N, N)\right) & \text { if } \pi_{S}(N, N) \geq v_{I D} \text { and } \\
\left(\pi_{F}(N, \emptyset)-v_{I D}, v_{I D}\right) & \text { if } \pi_{S}(N, N)<v_{I D} .
\end{array}
$$

Note that the above specification incorporates the notion of information leakage: The incumbent earns $\pi_{F}(N, N)$ when the employee leaves after an internal disclosure.

The bargaining outcome follows a Nash bargaining solution. We denote the bargaining power of the firm as $\alpha \in(0,1)$ and the bargaining power of the employee as $1-\alpha \cdot{ }^{17}$ Then, when $\pi_{S}(N, N) \geq v_{I D}$, the payoff of the firm is

$$
s_{F} \equiv \pi_{F}(N, N)+\alpha\left(\pi_{F}(N, \emptyset)-\pi_{F}(N, N)-\pi_{S}(N, N)\right),
$$

and the payoff of the employee is

$$
s_{E} \equiv \pi_{S}(N, N)+(1-\alpha)\left(\pi_{F}(N, \emptyset)-\pi_{F}(N, N)-\pi_{S}(N, N)\right)
$$

\footnotetext{
${ }^{15}$ In Baccara and Razin (2007), we analyze a bargaining protocol that allows for information leakage and study its implications for the distribution of the rents in a firm.

${ }^{16}$ In Section 5.1, we consider the alternative of allowing the employee to commit to an outside option before the renegotiation starts, and discuss the robustness of our results to this setting.

${ }^{17}$ In Section 5, when we address the corporate governance of the firm, we assume that $n$ owners and $m$ new players need to be brought into the bargaining to develop the idea successfully. In that case, $\alpha \in(0,1)$ represents the collective bargaining power of the owners and $1-\alpha$ the collective bargaining power of the new players.
} 
Note that the renegotiation surplus $S \equiv \pi_{F}(N, \emptyset)-\pi_{F}(N, N)-\pi_{S}(N, N)$ tends to decrease if either the firm's or the employee's IPR on the new-product market are strong.

If $\pi_{S}(N, N)<v_{I D}$, there is no bargaining surplus, and the Nash bargaining solution payoffs are equal to the outside options-i.e., $\pi_{F}(N, \emptyset)-v_{I D}$ for the firm and $v_{I D}$ for the employee. To summarize, the payoff of the firm and the innovator, respectively, after an internal disclosure are

$$
\begin{array}{ll}
\left(\pi_{F}(N, \emptyset)-v_{I D}, v_{I D}\right) & \text { if } v_{I D} \geq \pi_{S}(N, N) \text { and } \\
\left(s_{F}, s_{E}\right) & \text { if } v_{I D}<\pi_{S}(N, N) .
\end{array}
$$

\section{$3 \quad$ Non-Verifiable Internal Disclosure $\left(v_{I D}=v\right)$.}

In this section, we assume that internal disclosure is not verifiable by a court. This is the case, for instance, when there is no verifiable intra-firm record of the ideas disclosed by the employees, or the firms do not have enough reputational concerns to be able to commit to a payment conditional on ideas' disclosure. Thus, the contract has to satisfy the condition $v_{I D}=v$.

The next Lemma characterizes the optimal decision of the innovator as a function of the contract $v$.

Lemma 1 (Innovator's choice) The innovator's optimal decision is as follows:

1. If $v>\pi_{S}(O, N)-c$, the employee does not innovate;

2. If $\pi_{S}(O, N)-c \geq v>\pi_{S}(N, N)$, the employee forms a spin-out;

3. If $v \leq \pi_{S}(N, N)$, two cases are possible:

(a) If $s_{E} \geq \pi_{S}(O, N)$, there is internal disclosure;

(b) If $s_{E}<\pi_{S}(O, N)$, the employee forms a spin-out.

Proof 1. If $v>\pi_{S}(O, N)-c$, the employee is better off not innovating and getting $v$ rather than innovating and getting the maximum between $v-c$ (through an internal disclosure, since $\left.v \geq \pi_{S}(N, N)\right)$ and $\pi_{S}(O, N)-c$ (through a spin-out). 2. In this case, an internal disclosure leads to $v-c$ (since $v \geq \pi_{S}(N, N)$ ), while forming a spin-out leads to $\pi_{S}(O, N)-c>v>v-c$. 3. In this case, since $v<\pi_{S}(N, N)$, an intra-firm renegotiation leads to a payoff of $s_{E}$. In the case of an internal disclosure, the innovator gets $s_{E}-c$, and 
in the case of a spin-out, the innovator gets $\pi_{S}(O, N)-c$. Note that, by not innovating, the employee gets $v<\pi_{S}(O, N)-c$; Thus, forming a spin-out dominates not innovating.

Let us now turn to the characterization of the optimal contract. The characterization depends on the employee's bargaining payoff, $s_{E}$, which, in turn, depends on the bargaining weight $\alpha$, on the employee's outside option $\pi_{S}(N, N)$, and on the bargaining surplus $S$. The bargaining weight $\alpha$ captures external characteristics of the bargaining parties, such as reputation concerns and bargaining skills. The other two determinants of the innovator's bargaining position depend on the type of innovation and the IPR environment, as outlined above.

Following point (3) of Lemma 1, it helps to separate two cases: In the first case, the employee's position in the renegotiation is strong $\left(s_{E} \geq \pi_{S}(O, N)\right)$, and in the second case, the employee's bargaining position in the renegotiation is weak $\left(s_{E}<\pi_{S}(O, N)\right)$. When the position of the employee in the renegotiation is strong, the firm anticipates a "reshuffling" of rents upon internal disclosure. In the next result, we illustrate how the anticipation of rent reshuffling affects the optimal contract.

Proposition 1 (Reshuffling Effect) If $s_{E} \geq \pi_{S}(O, N)$, the optimal contract is as follows:

1. If

$$
\pi_{F}(O, \emptyset)-\pi_{S}(O, N)+c \geq(1-\alpha) \pi_{F}(N, N)+\alpha\left(\pi_{F}(N, \emptyset)-\pi_{S}(N, N)\right),
$$

the firm sets $v=\pi_{S}(O, N)-c$ and the employee does not innovate;

2. Otherwise, the firm sets $v=0$, the employee innovates and he discloses his idea internally.

Proof If $s_{E} \geq \pi_{S}(O, N)$, by Lemma 1, internal disclosure can be promoted by setting $v<\pi_{S}(N, N)$. Note that, from the firm's point of view, an internal disclosure is better than a spin-out if

$$
\pi_{F}(O, N) \leq(1-\alpha) \pi_{F}(N, N)+\alpha\left(\pi_{F}(N, \emptyset)-\pi_{S}(N, N)\right) .
$$


However, this condition is always satisfied since $\pi_{F}(O, N)<\pi_{F}(N, N)$ and $\pi_{F}(O, N)<$ $\pi_{F}(N, \emptyset)-\pi_{S}(N, N)$ (the second inequality follows from $\pi_{F}(O, N)+\pi_{S}(N, N)<\pi_{F}(N, N)+$ $\left.\pi_{S}(N, N)<\pi_{F}(N, \emptyset)\right)$. On the other hand, by Lemma 1, discouraging innovation requires setting $v=\pi_{S}(O, N)-c$. Thus, if condition (1) is satisfied, discouraging innovation dominates an internal disclosure and vice-versa.

Proposition 1 focuses on the case in which the innovator's bargaining position in a renegotiation is relatively strong - that is, $s_{E} \geq \pi_{S}(O, N)$. In this case, by Lemma 1 , the incumbent can ensure internal disclosure by setting $v<\pi_{S}(N, N)$, and guarantee himself a payoff of $s_{F}>\pi_{F}(N, N)$.

Alternatively, by Lemma 1 , the incumbent can promote a spin-out by setting $v \in$ $\left(\pi_{S}(N, N), \pi_{S}(O, N)-c\right]$. However, since $\pi_{F}(N, N) \geq \pi_{F}(O, N)$, a spin-out is always dominated by an internal disclosure.

Finally, by setting any $v \geq \pi_{S}(O, N)-c$, the incumbent discourages innovation. In particular, a high $v$ modifies the innovator's outside option in the renegotiation to remain in the firm. Thus, by setting $v=\pi_{S}(O, N)-c$, the firm prevents both internal disclosure and a spin-out, and maintains the status quo.

Thus, the two options available to the incumbent are promoting internal disclosure or maintaining the status quo. The incumbent may prefer to maintain the status quo fearing the reshuffling of rents that an intra-firm renegotiation implies. Condition (1) suggests that this reshuffling effect is more severe the stronger the employee's bargaining position in the renegotiation is. In particular, the reshuffling effect increases as $\pi_{F}(N, N)$ decreases (i.e., the weaker the IPR of the incumbent on the new-product market) and the higher $\pi_{S}(N, N)$ (i.e., the stronger the IPR of the employee on the new-product market).

Let us focus now on the case in which the innovator's bargaining position in an internal disclosure is weak - that is, $s_{E}<\pi_{S}(O, N)$. In this case, the incumbent's lack of commitment to compensate the innovator upon internal disclosure causes an intra-firm hold-up problem. Thus, by Lemma 1, an internal disclosure cannot occur in equilibrium, and the innovator will leave the firm as soon as he has an idea. The only way for the firm to prevent a spin-out is to set a high $v$ (in particular, $v=\pi_{S}(O, N)-c$ ) to effectively discourage innovation. Thus, the incumbent will allow a spin-out to form if and only if $\pi_{F}(O, N)$ (i.e., the firm's payoff in the case of a spin-out), is higher than $\pi_{F}(O, \emptyset)-\left(\pi_{S}(O, N)-c\right)$, and will discourage innovation otherwise. 
Proposition 2 (Inner Hold-Up) If $s_{E}<\pi_{S}(O, N)$, the optimal contract is as follows:

1. When

$$
\pi_{F}(O, N) \geq \pi_{F}(O, \emptyset)-\pi_{S}(O, N)+c
$$

the incumbent sets $v=0$ and a spin-out occurs in equilibrium;

2. Otherwise, the incumbent sets $v=\pi_{S}(O, N)-c$, and the employee does not innovate.

Note that both outcomes in Proposition 2 are inefficient. This suggests that, in an environment in which employees' IPR vis-à-vis the original firm (such as non-compete agreements) are weak, new ideas will tend to be developed in new start-ups rather than in established firms. This result is supported by a large body of empirical work, which shows how in states in which non-compete agreements are weakly enforced (e.g., California), established firms tend to be less innovative than start-ups. ${ }^{18}$

Finally, note that condition (2) implies that a spin-out is more likely to occur the higher $\pi_{F}(O, N)+\pi_{S}(O, N)$ is with respect to $\pi_{F}(O, \emptyset)$ - that is, the lower the competition between the old and the new product and the more profitable the new idea is when implemented in a spin-out. Proposition 2 also implies that, while substantial new ideas will always be implemented through spin-outs, less-profitable ideas will not be developed either within or outside the firm.

\section{Innovation Bonuses $\left(v \neq v_{I D}\right)$}

In this section, we consider the case in which firms are able to commit to a payment conditional on the disclosure of a new idea. Although internal disclosure is typically difficult to verify in court, there are some examples of firms that are able (e.g., by developing a reputation) to make such commitments. Indeed, Harryson (1996) reports that a frequently used instrument among Japanese firms is an internal-proposal system for new ideas usually connected with a reward scheme. Also, Herstatt and al. (2006), after surveying a representative sample of Japanese firms, report that about $30 \%$ of them use databases to store and process new product ideas sought internally. Moreover, innovation bonus systems as a

\footnotetext{
${ }^{18}$ For example, see Saxenian (1996) and the references therein.
} 
way to reward creative employees have been implemented increasingly often in Europe. ${ }^{19}$

We now allow for contracts to have $v \neq v_{I D}$. As before, we first characterize the innovator's choice as a function of the contract $\left(v, v_{I D}\right)$. The incumbent now has an additional tool to induce internal disclosure. Indeed, even if the bargaining position of the innovator is low - that is, in the case $s_{E}<\pi_{S}(O, N)$ - the incumbent can promote internal disclosure by committing to a large enough innovation bonus $v_{I D}$. Thus, the inner holdup problem illustrated in Proposition 2 disappears. In the next result, we show that the presence of innovation bonuses allows the incumbent to always reach the efficient bargaining outcome.

Proposition 3 When internal disclosure is verifiable, it always occurs in equilibrium.

Proof Note that the innovator's optimal choice is as follows: (i) If $v \geq \max \left[\pi_{S}(O, N)-\right.$ $\left.c, z_{E}-c\right]$, the employee is silent; (ii) If $\pi_{S}(O, N)-c \geq \max \left[v, z_{E}-c\right]$, the employee forms a spin-out; (iii) If $z_{E} \geq \max \left[v, \pi_{S}(O, N)-c\right]$, there is internal disclosure. As before, let us distinguish two cases: the case in which the innovator's bargaining power in a renegotiation is relatively high $\left(s_{E} \geq \pi_{S}(O, N)\right)$, and the case in which it is relatively low $\left(s_{E}<\pi_{S}(O, N)\right)$.

First, suppose that $s_{E} \geq \pi_{S}(O, N)$. In this case, the firm has the following options: (i) Choose $v=\pi_{S}(O, N)-c, v_{I D}=\pi_{S}(N, N)$, and the employee does not innovate. The firm gets $\pi_{F}(O, \emptyset)-\pi_{S}(O, N)+c$. (ii) Choose $v_{I D}=\pi_{S}(O, N), v=0$, and the employee internally discloses. The firm gets $\pi_{F}(N, \emptyset)-\pi_{S}(O, N)$. Or, choose $v_{I D}=v=0$, there is still internal disclosure, and firm gets $s_{F}$. From firm's point of view, the first option dominates the second since $s_{E} \geq \pi_{S}(O, N)$, so $\pi_{F}(N, \emptyset)-\pi_{S}(O, N) \geq \pi_{S}(N, \emptyset)-s_{E}=s_{F}$. (iii) Choose $v_{I D}=\pi_{S}(N, N), v=0$, the employee spins out out. The firm gets $\pi_{F}(O, N)$.

Suppose now that $s_{E}<\pi_{S}(O, N)$. The firm has now the following options: (i) Choose $v=\pi_{S}(O, N)-c, v_{I D}=\pi_{S}(N, N)$ and the employee does not innovate. The firm gets $\pi_{F}(O, \emptyset)-\pi_{S}(O, N)+c$. (ii) Choose $v_{I D}=\pi_{S}(O, N), v=0$, and the employee internally discloses. The firm gets $\pi_{F}(N, \emptyset)-\pi_{S}(O, N)$ (iii) Choose $v_{I D}=0, v=0$,and the employee spins out out. The firm gets $\pi_{F}(O, N)$.

\footnotetext{
${ }^{19}$ For example, data from the Federation of Enterprises in Belgium (FEB) show that, in 2006, about 50\% of local companies had internal policies to encourage internal innovation, and about $20 \%$ of them rewarded employees who discover innovative ideas. To encourage the distribution of innovation bonuses, the FEB negotiated and tabled guidelines for innovation bonuses exempt from social security and income taxes (see "The Innovation bonus, or how to reward creative employees," FBE publication, 2006).
} 
Note that, for any option chosen by the firm, the payoff of the firm does not change in the two cases $s_{E} \lessgtr \pi_{S}(O, N)$. Then, internal disclosure dominates discouraging innovation since, if $c<\pi_{F}(N, \emptyset)-\pi_{F}(O, \emptyset)$, we have

$$
\pi_{F}(N, \emptyset)-\pi_{S}(O, N)>\pi_{F}(O, \emptyset)-\pi_{S}(O, N)+c
$$

Moreover, note that, from the firm's point of view, an internal disclosure is always better than a spin-out, since

$$
\pi_{F}(O, N)<\pi_{F}(N, \emptyset)-\pi_{S}(O, N)
$$

Proposition 3 implies that, if disclosure is verifiable, in addition to the inner hold-up problem, the reshuffling effect also disappears. Indeed, when internal disclosure was not verifiable and $s_{E}$ was relatively high, the firm had only one tool, $v$, to control both the employee's decision to innovate and the rents he could secure in the renegotiation. In particular, in that case, the only way the firm could encourage internal disclosure was to allow the employee to get a high rent, $s_{E}$, in the renegotiation. Now, since $v$ and $v_{I D}$ can be separated, the firm can ensure that the employee internally discloses (by creating a wedge between $v$ and $v_{I D}$ ) and, at the same time, it can lower the rents the employee gets in the renegotiation by committing to a high enough $v_{I D}$ (which is still lower than $s_{E}$ ) and changing the employee's outside option in the renegotiation.

\section{Extensions}

\subsection{Innovator Commitment}

The employee's lack of commitment in choosing his outside options is a driving assumption in the above results. Indeed, Proposition 3 hinges on the firm's ability to use disclosure bonuses to manipulate the innovator's outside option in the bargaining and lower his bargaining position. Indeed, the firm can hurt the credibility of a spin-out threat in the case of renegotiation breakdown by setting $v_{I D}$ larger or equal to $\pi_{S}(N, N)$-i.e. the innovator's payoff in a spin-out facing the competition of the original firm. This strategy allows the firm to pay the innovator a relatively low $v_{I D}$ and still promote innovation within the firm.

However, innovators often have the possibility of committing to a course of action to 
follow upon renegotiation breakdown. Indeed, employees are naturally the first movers in that, initially, they are the only ones aware of their innovation. This gives them the time and possibility to prepare their bargaining stance. For example, the employee could try to influence the (perceived) outside option he would choose upon renegotiation breakdown. One way to do this could be to initiate the process of forming a spin-out by forming alliances with people outside the firm. In this section, we check the implications of the employee's commitment ability for the analysis in Section 4. Therefore, we maintain the assumption of verifiable disclosure.

To describe the innovator's commitment ability, we follow Nash (1953) in modeling the bargaining negotiation as a two-stage game in which the parties choose their outside options first, and then they split the rents according to a Nash bargaining solution. ${ }^{20}$ As discussed in Section 2, upon renegotiation failure, while the firm is committed to the original contract $\left(v, v_{I D}\right)$, the employee has the choice of staying within the firm under the original contract (securing a payoff of $v_{I D}$ for himself and $\pi_{F}(N, \emptyset)-v_{I D}$ for the original firm) or leaving the firm and forming a spin-out that will compete with the original firm on the new-product market (securing a payoff of $\pi_{S}(N, N)$ for himself and $\pi_{F}(N, N)$ for the original firm). Here, we assume that the employee selects his outside option before the bargaining starts to maximize his payoff in the Nash bargaining game. After the outside options are pinned down in the first stage, the bargaining outcome follows the Nash bargaining solution, where, as before, the bargaining weight of the firm is $0<\alpha<1$, and the bargaining weight of the employee is $1-\alpha$.

Thus, the firm's and the employee's outside option payoffs implied by the employee's (optimal) choice are now

$$
\begin{array}{ll}
\left(\pi_{F}(N, N), \pi_{S}(N, N)\right) & \text { if } s_{E} \geq v_{I D} \text { and } \\
\left(\pi_{F}(N, \emptyset)-v_{I D}, v_{I D}\right) & \text { if } s_{E}<v_{I D},
\end{array}
$$

which imply the following payoffs in the renegotiation

$$
\begin{array}{ll}
\left(s_{F}, s_{E}\right) & \text { if } s_{E} \geq v_{I D} \text { and } \\
\left(\pi_{F}(N, \emptyset)-v_{I D}, v_{I D}\right) & \text { if } s_{E}<v_{I D} .
\end{array}
$$

\footnotetext{
${ }^{20}$ Indeed, when multiple threat points are possible, Nash (1953) endogenizes the outside option as the noncooperative (Nash) equilibrium of the following two-stage game: (i) The two players $i=1,2$ independently choose (possibly mixed) threats $m_{i}, i=1,2$; (ii) The player's final payoffs are given by the Nash-bargaining solution relative to the disagreement point determined in Stage 1. See, also, Gomes and Bloch (2006).
} 
The possibility of committing to a course of action upon negotiation breakdown improves the employee's bargaining position. In particular, it is not enough for the firm to commit to a payment equal to $\pi_{S}(N, N)$ to prevent the innovator from appropriating $s_{E}$ in the bargaining. Indeed, when an innovator can commit to a course of action, he will always be able to appropriate at least $s_{E}$ in case of an internal disclosure. This is an attractive option when $s_{E} \geq \pi_{S}(O, N)$, that is, the renegotiation payoff is higher than what the innovator would appropriate by forming a spin-out.

Proposition 4 (Innovator's Commitment) If the innovator is able to commit to an outside option, in equilibrium there is always internal disclosure.

Proof Let us first suppose that $s_{E} \geq \pi_{S}(O, N)$. In this case, from the innovator's perspective, internal disclosure (yielding at least $s_{E}$ ) always dominates a spin-out (yielding $\left.\pi_{S}(O, N)\right)$. Because of the innovator's commitment ability, preventing internal disclosure requires setting $v=s_{E}-c, v_{I D}=0$. However, it is easy to check that

$$
s_{F} \geq \pi_{F}(O, \emptyset)-s_{E}+c
$$

since $c<\pi_{F}(N, \emptyset)-\pi_{F}(O, \emptyset)$. Thus, an internal disclosure is optimal from the firm's perspective. If $s_{E}<\pi_{S}(O, N)$, discouraging innovation requires setting $v=\pi_{S}(O, N)-c$, $v_{I D}=0$, and internal disclosure requires setting $v_{I D}=\pi_{S}(O, N), v=0$. Then, internal disclosure dominates discouraging innovation since, as $c<\pi_{F}(N, \emptyset)-\pi_{F}(O, \emptyset)$, we have

$$
\pi_{F}(N, \emptyset)-\pi_{S}(O, N)>\pi_{F}(O, \emptyset)-\pi_{S}(O, N)+c .
$$

Moreover, since we have

$$
\pi_{F}(N, \emptyset)-\pi_{S}(O, N)>\pi_{F}(O, N)
$$

internal disclosure is better than a spin-out from the firm's perspective.

The equilibrium outcomes described in Proposition 4 could turn out to be problematic for the firm. Indeed, note that if $s_{E} \geq \pi_{S}(O, N)$, the firm in equilibrium appropriates $s_{F}$, which could be lower than what the firm could appropriate in the absence of intra-firm renegotiation. The next result shows that, when the innovator has the ability to commit to a course of action upon renegotiation break-down, the firm may prefer to commit to a 
policy not to negotiate or implement any innovative idea, even in the case in which ideas' disclosure is verifiable.

Proposition 5 (Firm's Commitment) Suppose that the innovator is able to commit to an outside option, and the firm not to engage in any renegotiation with innovative employees. Then, there is always internal disclosure, and the firm sometimes prefers to commit not to renegotiate.

Proof Suppose that $s_{E} \geq \pi_{S}(O, N)$. In this case, the firm can induce internal disclosure by setting $v=0, v_{I D}=\pi_{S}(O, N)$ and committing not to renegotiate. The firm can discourage innovation by setting $v=\pi_{S}(O, N)-c, v_{I D}=0$ and committing not to renegotiate, and can let a spin-out form by setting $v_{I D}=v=0$ and committing not to renegotiate. From the firm's perspective, internal disclosure is optimal since, as $c<\pi_{F}(N, \emptyset)-\pi_{F}(O, \emptyset)$, we have

$$
\pi_{F}(N, \emptyset)-\pi_{S}(O, N)>\pi_{F}(O, \emptyset)-\pi_{S}(O, N)+c
$$

and

$$
\pi_{F}(N, \emptyset)-\pi_{S}(O, N)>\pi_{F}(O, N)
$$

The $s_{E}<\pi_{S}(O, N)$ case is identical to Proposition 4.

Recall that the outcome described in Proposition 5 is consistent with the evidence of firms that introduce a policy not to renegotiate contracts upon innovation disclosure (in particular, recall the RCA one-dollar policy described in the Introduction).

\subsection{Corporate Governance and New Players}

In this section, we model the corporate governance of the incumbent firm assuming that the initial shareholders are the decision-makers in the ex-post renegotiation with innovative employees. This assumption fits a scenario in which the firm is a small partnership, as is often the case with high-tech start-ups. Moreover, we allow for new players to be included in the development of the new idea into a product (such as venture capitalists needed for funding or specialized engineers).

The bargaining position of each of the initial owners is influenced by the number of original owners $n$, the $m$ new players that need to be brought into the firm (e.g., the innovator, 
the venture capitalists, banks, etc) and the information leakage upon internal disclosure. For simplicity, we assume that the bargaining power among the owners, innovator (which we denote as player $i=n+1)$ and all the other new players involved in the development is allocated equally. ${ }^{21}$ Thus, we assume that the allocation of bargaining power for all the players involved in the renegotiation is $\left(\frac{1}{n+m}, . ., \frac{1}{n+m}\right)$.

We are interested in addressing how the distribution of shares in the original firm and the presence of the new players affect the incumbent's attitude towards promoting innovation. Note that, in this analysis, we focus on the case of non-verifiable disclosure, i.e., $v=v_{I D}$. Also, we assume that, for internal disclosure to occur, every original owner must prefer implementing the new product to the outside option (determined by the innovator's choice as described in Section 2.4). Also, the shareholders must agree on the initial contract offered to the employee (assume the default contract in case of disagreement is $v=0$ ).

In this environment, an intra-firm renegotiation upon internal disclosure would lead to the following outcomes:

(i) If $v \leq \frac{\pi_{S}(N, N)}{m}$, then

$$
\widetilde{s}_{E}=\frac{1}{m} \pi_{S}(N, N)+\frac{1}{n+m}\left(\pi_{F}(N, \emptyset)-\pi_{S}(N, N)-\pi_{F}(N, N)\right) .
$$

For $i=1, . ., n$, we have

$$
\widetilde{s}_{i}=\frac{1}{n} \pi_{F}(N, N)+\frac{1}{n+m}\left(\pi_{F}(N, \emptyset)-\pi_{S}(N, N)-\pi_{F}(N, N)\right) .
$$

(ii) If $v>\frac{\pi_{S}(N, N)}{m}$, the old contract is the outside option in the renegotiation and the renegotiation has zero surplus.

Proposition 6 (Corporate Governance and Reshuffling Effect) If $\widetilde{s}_{E} \geq \frac{\pi_{S}(O, N)}{m}$, the optimal contract is as follows:

1. If

$$
\pi_{F}(O, \emptyset)-\frac{\pi_{S}(O, N)}{m}>\frac{m}{(n+m)} \pi_{F}(N, N)+\frac{n}{n+m}\left(\pi_{F}(N, \emptyset)-\pi_{S}(N, N)\right)
$$

\footnotetext{
${ }^{21}$ The results extend easily to the case in which the bargaining power is distributed asymmetrically between the innovator and the other new players.
} 
for all $i \in 1, \ldots, n$, the firm sets $v=\frac{\pi_{S}(O, N)}{m}$ and the employee does not innovate.

2. Otherwise, the firm sets $v=0$ and the employee innovates and discloses his idea internally.

Proof If $\widetilde{s}_{E} \geq \frac{1}{m} \pi_{S}(O, N)$, the choices for one of the incumbent's owners are as follows: (i) Setting $v=0$, inducing internal disclosure and appropriating $\widetilde{s}_{i}$; (ii) setting $v=\frac{1}{m} \pi_{S}(N, N)$, inducing a spin-out and appropriating $\frac{1}{n} \pi_{F}(O, N)$; or (iii) setting $v=\frac{1}{m} \pi_{S}(O, N)-c$, discouraging the employee to innovate and appropriating $\frac{1}{n}\left(\pi_{F}(O, \emptyset)-\right.$ $\left.\frac{1}{m} \pi_{S}(O, N)+c\right)$.

Note that a spin-out is dominated by an internal disclosure as

$$
\frac{\pi_{F}(O, N)}{n}<\widetilde{s}_{i}=\frac{m}{n(n+m)} \pi_{F}(N, N)+\frac{1}{n+m}\left(\pi_{F}(N, \emptyset)-\pi_{S}(N, N)\right) .
$$

Thus, the firm discourages innovation if and only if condition (3) is met.

Proposition 6 implies that the reshuffling effect is stronger the lower the new bargaining position of the owner (represented by $\frac{1}{n+m}$ ). However, it is easy to see that, as $n$ increases, condition (3) is easier to satisfy. Thus, firms that are owned by a small number of shareholders will tend to discourage innovation more often than firms in which the ownership is dispersed. This is because, as the number of original owners increases, an owner has less to lose from the introduction of a fixed number $m$ of new players, but will tend to benefit from the potential increase of the firm's profits due to innovation. Second, note that the higher the number of new players brought into the firm for the development of the new idea, the more the firm will be prone to discourage innovation. This finding is consistent with the observation that Japanese firms tend to rely less on venture capitalists and more on internal finances or bank debt than U.S. firms, and, at the same time, established firms have been consistently successful at fostering innovation. ${ }^{22}$

Let us move to the case $\widetilde{s}_{E}<\frac{1}{m} \pi_{S}(O, N)$. In this case, an internal disclosure never occurs in equilibrium due to the inner hold-up problem illustrated in Proposition 2.

\footnotetext{
${ }^{22}$ See Shishido (2008) and Osaki (2008).
} 
Proposition 7 (Corporate Governance and Inner Hold-Up) If $\widetilde{s}_{E}<\frac{1}{m} \pi_{S}(O, N)$, the optimal contract is as follows:

1. If

$$
\pi_{F}(O, N)>\pi_{F}(O, \emptyset)-\frac{\pi_{S}(O, N)}{m},
$$

the firm sets $v=0$ and a spin-out occurs in equilibrium;

2. Otherwise, the firm sets $v=\frac{1}{m} \pi_{S}(O, N)-c$ and innovation is discouraged.

Proof The claims follows immediately from the fact that, from the owners' perspective, a spin-out is better than discouraging innovation if

$$
\frac{\pi_{F}(O, N)}{n}>\frac{\pi_{F}(O, \emptyset)-\frac{\pi_{S}(O, N)}{m}}{n} .
$$

Proposition 7 implies that the inner hold-up effect is independent of how dispersed the original firm's ownership is. However, note that spin-outs are more likely to occur the higher is the innovator's share in the spin-out, represented by $\frac{1}{m}$. This is because if many new players are needed to develop the new idea into a product, the appropriation rate of the innovator in the spin-out is low, and discouraging innovation is cheaper to achieve. Thus, the more ambitious or capital-intensive ideas are, the more likely they are to be discouraged and less likely to be implemented through a spin-out.

\section{Conclusion}

In this paper, we analyze the incentives to promote innovation in firms. We find that, when IPR protect the position of innovative employees in the intra-firm renegotiation process, the firm may have an incentive to stifle innovation, fearing the rent reshuffling caused by innovation implementation. On the other hand, when the innovator's IPR in the firm are weak, in order to prevent expropriation, the innovator may leave the firm to form a spinout without first trying to disclose his idea internally. If that case, the firm may set up an ex-ante compensation scheme to prevent spin-out formation. We show that, if innovation bonuses are a viable contractual tool, they are always sufficient to implement the bargaining efficient outcome. Moreover, we study the robustness of our results in a setting in which the innovator has the ability to commit to leaving the firm before the renegotiation starts. 
In this case, to counteract the rent loss due to the innovator's commitment, the firm may respond by committing never to renegotiate contracts upon internal disclosure. Finally, we show that the incentives to stifle innovation are stronger if the firm ownership is more concentrated.

\section{References}

[1] Anton J.J.and D.A.Yao (1994), "Expropriation and Inventions: Appropriable Rents in the Absence of Property Rights," American Economics Review, 84-1.

[2] Anton J.J.and D.A.Yao (1995), "Start-ups, Spin-offs and Internal Projects," Journal of Law, Economics and Organization, 11 (2).

[3] d'Aspremont C., S. Bhattacharya and L.A. Gerard-Varet (2000), "Bargaining and Sharing Innovative Knowledge," Review of Economic Studies, 67, 255-271.

[4] Baccara M. and R.Razin (2007), "Bargaining over New Ideas: Rent Distribution and Stability of Innovative Firms," Journal of the European Economics Association, December 2007, Vol 5, Issue 6, pp.1095-1129.

[5] Bhattacharya S. and S. Guriev (2004), "Knowledge Disclosure, Patents and Optimal Organization of Research and Development," Mimeo.

[6] Christensen C. (1997), "The Innovator's Dilemma," Harvard Business School Press.

[7] Foster R., and S. Kaplan (2001), "Creative Distrucion," Doubleday.

[8] Franco A. and D.Filson (2002), "Spin-Outs: Knowledge Diffusion through. Employee Mobility," Federal Reserve Bank of Minneapolis Working Paper

[9] Franco A. and M. Mitchell (2005), "Covenants not to Compete, Labor Mobility and Industry Dynamics," Working Paper.

[10] Gomes and Bloch (2006), "Contracting with Externalities and Outside Options," Journal of Economic Theory, 172-201

[11] Harryson S. (1996), "Improving R\&D performance through Networking: Lessons from Canon and Sony," Arthur D. Little-Prism, Fourth Quarter 1996. 
[12] Hellmann T. (2005), "When do Employees become Entrepreneurs?," Working Paper.

[13] Hellmann T. and E. Perotti (2005), "Circulation of Ideas: Firms versus Markets," Working Paper.

[14] Herstatt C., B.Verworn, C.Stockstrom, A.Nagahira and O.Takahashi (2006), "Fuzzy Front End: Practices in Innovating Japanese Companies," in Management of Technology and Innovation in Japan, edited by C.Herstatt, C.Stockstrom, H. Tschirky and A.Nagahira, Springer Ed.

[15] Klepper, S. (2001), "Employee Startups in High Tech Industries," Industrial and Corporate Change, Vol. 10 (3).

[16] Klepper S. and S.Sleeper (2000), "Entry by Spin-Offs," Mimeo.

[17] Lewis T.R. and D. Yao (2003), "Innovation, Knowledge Flow and Worker Mobility," Mimeo.

[18] McNamara C (1999) "Facilitator's Guide to Nonprofit Strategic Planning," http://www.mapnp.org/library.

[19] Osaki S. (2008), "Innovation and Regulation of the Capital Markets in Japan," Mimeo.

[20] Pakes, A. and S. Nitzan (1983), "Optimum Contracts for Research Personnel, Research Employment, and the Establishment of "Rival" Enterprises," Journal of Labor Economics, Vol. 1 (4) pp. 345-65.

[21] Rauch J.E. and J. Watson (2005), "Are There Too Many Entrepreneurs? A Model of Client-Based Entrepreneurship," Mimeo.

[22] Saxenian A. (1996), "Regional Advantage: Culture and Competition in Silicon Valley and Route 128," Harvard University Press.

[23] Shishido Z. (2008), "Why Japanese Entrepreneurs Do Not Give Up Control to Venture Capitalists," Mimeo.

[24] Scotchmer S. (1991), "Standing on the Shoulders of Giants: Protecting Cumulative Research and the Patent Law," Journal of Economic Perspectives 5(1). Reprinted in The Economics of Technical Change, Edwin Mansfield and Elizabeth Mansfield, eds, Edward Elgar Publishing Company, 1993. 
[25] Scotchmer S. (2005), "Standing on the Shoulders of Giants: Protecting Cumulative Research", in "Innovation and Incentives," forthcoming MIT Press.

[26] Schwartz E.I. (2002) "The Last Lone Inventor: A Tale of Genius, Deceit, and the Birth of Television," Harper Collins Ed.

[27] Stole L.A. and J. Zweibel (1994), "Intra Firm Bargaining Under Non Binding Contracts" The Review of Economic Studies, 63.

[28] Wolinsky A. (2000), " A Theory of The Firm With Non Binding Employment Contracts" Econometrica, 69.

[29] Välikangas L., M. Gibbert (2005), "Boundary-Setting Strategies for Escaping Innovation Traps," MIT Sloan Management Review. 